\title{
Specificity of an Isolated Salivary Factor Material to Cystic Fibrosis
}

\author{
J. E. IMPERO, G. M. HARRISON, AND T. E. NELSON ${ }^{(39)}$
}

Fleming Department of Rehabilitation, Baylor College of Medicine, Houston, Texas, USA

\begin{abstract}
Summary
An oyster gill ciliostatic factor material has been isolated from the saliva of patients with cystic fibrosis (CF) by utilizing its ability to bind to $\alpha$-amylase. It was quantitatively assayed by its ability to reversibly inhibit rabbit muscle glycogen debranching enzyme. The specificity of this CF factor material was investigated by comparing activities from the saliva of CF homozygotes (patients) varying in age, sex, and the severity of the disease; CF obligate heterozygotes (carriers); normal control subjects who had no family history of CF; non-CF asthmatic and allergic bronchitis patients; non-CF immunologically deficient patients with chronic respiratory problems; non-CF juvenile diabetic patients; non-CF pancreatic insufficiency patients; non-CF patients with obstructive liver cirrhosis; and non-CF patients with ectodermal dysplasia. The results show that the CF factor material isolated from CF saliva is specific to subjects with cystic fibrosis and is not associated with similar nonCF chronic disease states, nor is it produced as a result of an organ pathology associated with $C F$. There was no correlation between the amount of factor present in an individual CF homozygote sample and the severity of the disease. In the case of both the CF homozygote and heterozygote samples, there was also no correlation in either age or sex and the amount of factor present. The degree of inhibition produced by $\mathrm{CF}$ homozygotes compared to CF heterozygotes is characteristic of the autosomal recessive mode of inheritance of $\mathrm{CF}$. This finding appears to associate the isolated $C F$ factor material with the affected $C F$ gene and suggests that the factor material is related in some way to the genetic lesion in $\mathbf{C F}$.
\end{abstract}

\section{Speculation}

These studies indicate that the salivary cystic fibrosis factor material isolated by the glycogen-complex method is in some way dependent on the cystic fibrosis gene and is not associated with similar non-cystic fibrosis chronic disease states or produced as a result of the pathologic alterations in those organs commonly affected in cystic fibrosis.

Cystic fibrosis (CF) is the most common generalized lethal hereditary disorder found among Caucasians. It has been established that $\mathrm{CF}$ is a congenital disease inherited as an autosomal recessive genetic trait affecting males and females with equal frequency. The frequency of asymptomatic heterozygote carriers of the CF gene in the Caucasian population is about $5 \%(5,26$, 28).

In $\mathrm{CF}$, there is a widespread dysfunction of the exocrine glands (28). In homozygotes, mucus secretions are thought to obstruct organ secretory passages, giving rise to chronic pulmonary disease, pancreatic insufficiency, hepatic cirrhosis, diabetes, and intestinal obstruction (28). In 1967, Spock et al. (34) reported the presence of a factor in the serum of patients with $C F$ and in obligate heterozygotes (carriers), but not from most normal controls. The presence of this factor disorganized the beat of cilia (dyskinesis) in rabbit tracheal explants. Since then, the presence of putative factors has been reported in biologic fluids and/or fluids containing cultured fibroblasts, lymphocytes, and amniotic cells from $\mathrm{CF}$ patients and obligate heterozygotes (for a review, see Ref. 4). Various bioassays have been developed for the detection of these CF factors. These include the oyster gill ciliary assay developed by Bowman et al. (2) and modified by Schmoyer et al. (32) (cf. Ref. 4).

We have recently developed an enzymatic method to detect a factor isolated from CF saliva. This enzymatic method utilizes the finding that the purified factor inhibits mammalian glycogen debranching enzyme (12). The enzymatic method is rapid, quantitative, can be used on a routine basis, and avoids the uncertainties inherent in bioassays $(12,15)$. The noncompetitive type of inhibition produced by the isolated factor material on the activity of the debranching enzyme gives an indication of the chemical nature of the factor as has been discussed (15).

In $\mathrm{CF}$ saliva and serum, this ciliostatic factor has been associated with $\alpha$-amylase $(1,6,7)$. Using the enzyme inhibition assay (12), a method for the isolation and purification of a ciliostatic CF factor from whole saliva has been developed (15). The isolation method utilizes the fact that the factor material forms a complex with $\alpha$-amylase in saliva and remains bound to the amylase through subsequent purification of the enzyme. The amylase is purified from whole CF saliva by a glycogen-complex method, and the factor is then separated from the amylase by dialysis (15). The CF factor material isolated by the glycogen method is a potent ciliostatic agent (15). The activity of the isolated factor material is proportional to its concentration in both the oyster gill ciliostatic assay and the debranching enzyme inhibition assay (15). The factor material when isolated from the amylase is in the form of an apparent factor-peptide complex (17-19).

In the case of the oyster gill ciliostatic bioassay, it has been implied that the presence of a "CF factor" was related to the etiology of CF because it was not found in normal individuals or in individuals having other chronic lung diseases such as allergic and asthmatic bronchitis $(8,16,23)$. These studies, although suggestive of the presence of a factor related to $\mathrm{CF}$, by no means establish either that it is specific to $\mathrm{CF}$ or that it is not produced by the other organ diseases related to $C F$ such as pancreatic insufficiency, liver and sweat gland dysfunction, or diabetes. Indeed, Conover et al. (3) have shown, using the rabbit tracheal bioassay, that a ciliary-dyskinesia factor found in CF serum is also present in non-CF individuals with immunologic and pulmonary disease.

To determine if the CF factor material that we have isolated from saliva was specific to $\mathrm{CF}$ and not the product of these other pathologic alterations associated with $\mathrm{CF}$, we have extended our initial study of patient groups (16).

\section{MATERIALS AND METHODS \\ COLLECTION OF SALIVA}

Saliva was donated by $\mathrm{CF}$ patients and their parents (obligate heterozygotes) at the Cystic Fibrosis Center at The Institute for Rehabilitation and Research in Houston, with the control saliva 
samples being obtained from research associates and their children who had no family history of CF. Salivary specimens were obtained from non-CF patients having obstructive liver cirrhosis and pancreatic insufficiency at the Houston V. A. Hospital. Salivary specimens from non-CF patients diagnosed as having juvenile diabetes, chronic allergy, or asthmatic bronchitis, or with chronic respiratory pathology related to immunologic deficiency were obtained at St. Luke's and Texas Children's Hospitals, Houston. Salivary specimens from non-CF patients with ectodermal dysplasia were obtained at the University of Texas Dental Branch, Houston. Samples (approximately $25 \mathrm{ml}$ ) of whole mixed saliva were collected from each individual without stimulatory aids to promote secretion. Upon collection, each sample was treated identically as described previously (15).

\section{ANALYTICAL PROCEDURES}

The activity of rabbit muscle glycogen debranching enzyme amylo-1,6-glucosidase:4- $\alpha$-glucanotransferase (dextrin 6 - $\alpha$-glucosidase, EC 3.2.1.33/1,4- $\alpha$-D-glucan:1,4- $\alpha$-D-glucan 4- $\alpha$-glycosyltransferase, EC 2.4.1.25) was measured spectrophotometrically by detecting glucose production from glycogen phosphorylase limit dextrin as a substrate in the standard static assay described by Nelson et al. (29). Glucose was detected after the debranching enzyme reaction was stopped using a coupled hexokinase-glucose 6-phosphate dehydrogenase-NADP system. Absorbance of the $\mathrm{NADPH}$ produced was read at $340 \mathrm{~nm}$. The debranching enzyme reaction is linear with enzyme concentration to an optical density of approximately $0.360(29)$.

The effect of the CF factor on the inhibition of debranching enzyme was determined by addition of $25 \mu \mathrm{l}$ of the isolated factor to a total volume of $200 \mu \mathrm{l}$ in the standard assay. The enzymatic assay was run at $30^{\circ} \mathrm{C}$ and stopped after $10 \mathrm{~min}$ by heat denaturation in a boiling water bath for $90 \mathrm{sec}$. Glucose reagent $(0.80 \mathrm{ml})$ was added to each assay tube, and the absorbance was read in a spectrophotometer after $15 \mathrm{~min}$. The concentration of enzyme used to give $100 \%$ activity was adjusted to give a change in absorbance of approximately 0.250 in $10 \mathrm{~min}$ at $340 \mathrm{~nm}$ (approximately $0.04 \mu$ mole of glucose). Percentage of debranching enzyme inhibition was then calculated from the difference in enzyme activity in the presence and absence of the factor. The inhibition of the debranching enzyme by the isolated factor is linear with factor concentration up to approximately $70 \%$ inhibition (15).

The salivary CF factor material was isolated from whole saliva as described previously (15) by a glycogen-complex method which utilizes a modification of the procedure of Loyter and Schramm (25). The factor material was separated from the amylase by dialysis (15).

$\alpha$-Amylase ( $\alpha$-1,4-glucan-4-glycanohydrolase, EC 3.2.1.1) activity was measured as described previously by the dinitrosalicylate method (15). Protein was determined as described previously (15) using the Miller modification (27) of the Folin-Lowry method (24) with bovine serum albumin as a standard. The diagnostic pilocarpine iontophoresis method described by Gibson and Cooke (11) as modified by Sawyer et al. (31) was used for determining sweat sodium and chloride levels.

Statistical analysis of the data in Figure 1 was performed by using a one-way analysis of variance (36), a Student-NewmanKeuls post hoc comparison of groups (20), a Kolmogorov-Smirnov statistical distribution of data (22), and a Kruskal-Wallis analysis of variance by ranks (21). In Figure 2, each patient was clinically evaluated by the Shwachman-Kulczycki score before and during the course of this research to determine the severity of disease (33).

\section{MATERIALS}

Purified rabbit muscle glycogen debranching enzyme (amylo1,6-glucosidase:4- $\alpha$-glucanotransferase) was prepared according to the method of Watts and Nelson (35). Glycogen phosphorylase limit dextrin was prepared as described previously (29). Additional materials for the debrancher assay were obtained as described previously (15). Materials for the isolation of the $\mathrm{CF}$ factor material were obtained as described previously (15). All other chemicals and biochemicals were of the highest commercial grade available. Standard grade dialysis tubing was obtained from Arthur H. Thomas and Co., Philadelphia, PA. Deionized water of triple distilled quality was used after filtering through a $0.22 \mu$ filter.

\section{RESULTS}

The specificity of the factor material to CF was investigated by collecting identical amounts of whole saliva from each patient in the $\mathrm{CF}$ and non-CF groups. The samples were fractionated and assayed in an identical manner as previously described (15). Each sample was tested for the presence of the factor material by its ability to inhibit the debranching enzyme $(12,15)$. The reproducibility of the assay method is shown in Table 1 . The samples from each individual were obtained on a random basis over a period of several weeks. The individuals used were selected from the larger patient groups used in Figure 1.

To examine separately the various pathologic alterations in organs commonly associated with $\mathrm{CF}$ as a possible source of the factor, we used non-CF asthmatic and allergic bronchitis patients, non-CF immunologically deficient patients with chronic respiratory problems, non-CF patients with pancreatic insufficiency, non$\mathrm{CF}$ patients with obstructive liver cirrhosis, non-CF juvenile diabetes patients, and non-CF patients with ectodermal dysplasia. Ectodermal dysplasia is a congenital defect in which the sebaceous and sweat glands are absent or impaired (9). Sweat electrolyte levels are elevated to the CF range in individuals with ectodermal dysplasia who are able to sweat (30). The CF homozygotes (patients) varied in age, sex, and the severity of the disease. All of the CF heterozygotes (carriers) were known parents of CF patients. The normal (control) subjects used had no family history of CF. In addition, none of the other non-CF patients had a family history of CF so far as could be determined. The CF homozygote patients shown in Figure 1 were chosen to vary as much as possible in age and the severity of their disease. Individuals in the other groups were age and sex matched with the CF homozygotes as much as possible with the patient population available. In the case of the CF heterozygote population, only actual parents were used because there is no other way at present to determine $\mathrm{CF}$ heterozygotes. The results of this group study, expressed as percentage of inhibition of the debranching enzyme $(12,15)$ are shown in Figure 1.

In the statistical analysis of the data in Figure 1, the premise used (research hypothesis) was that there was no difference in mean response across groups 3 through 9 (normal, asthmatic, immunologic, pancreatic insufficiency, obstructive liver cirrhosis, diabetes, and ectodermal dysplasia) versus groups 1 (CF homozygotes) and 2 (CF heterozygotes). A one-way analysis of variance (36) revealed a significant difference between groups 1 and $2(P$ $<0.001$ ). A Student-Newman-Keuls post hoc comparison of the groups was performed (20) and revealed that both the groups 1 (CF homozygote) and 2 (CF heterozygote) values were significantly higher $(P<0.05)$ than all remaining groups (Table 2$)$. A Kolmogorov-Smirnov statistical evaluation (22) of group 2 (CF heterozygote) revealed a normal distribution of data; however, analysis of the remaining groups revealed the possibility of group 1 (CF homozygote) not having a normal sampling distribution. Therefore, intergroup differences were tested nonparametrically by the Kruskal-Wallis (21) analysis of variance by ranks. This technique can be applied when samples may not come from normal populations and/or when $\kappa$ population variances may be heterogenous. Significant differences $\left(\chi^{2}=69.536 ; P<0.001\right)$ were observed between group 1 and all other groups 2 to 9 using the Kruskal-Wallis test. These statistic results are shown in Table 2. The statistical analysis thus supports the research hypothesis and allows the conclusion that all of the CF homozygote values are higher and separated from all of the other values.

In the study shown in Figure 1, there was no significant corre- 


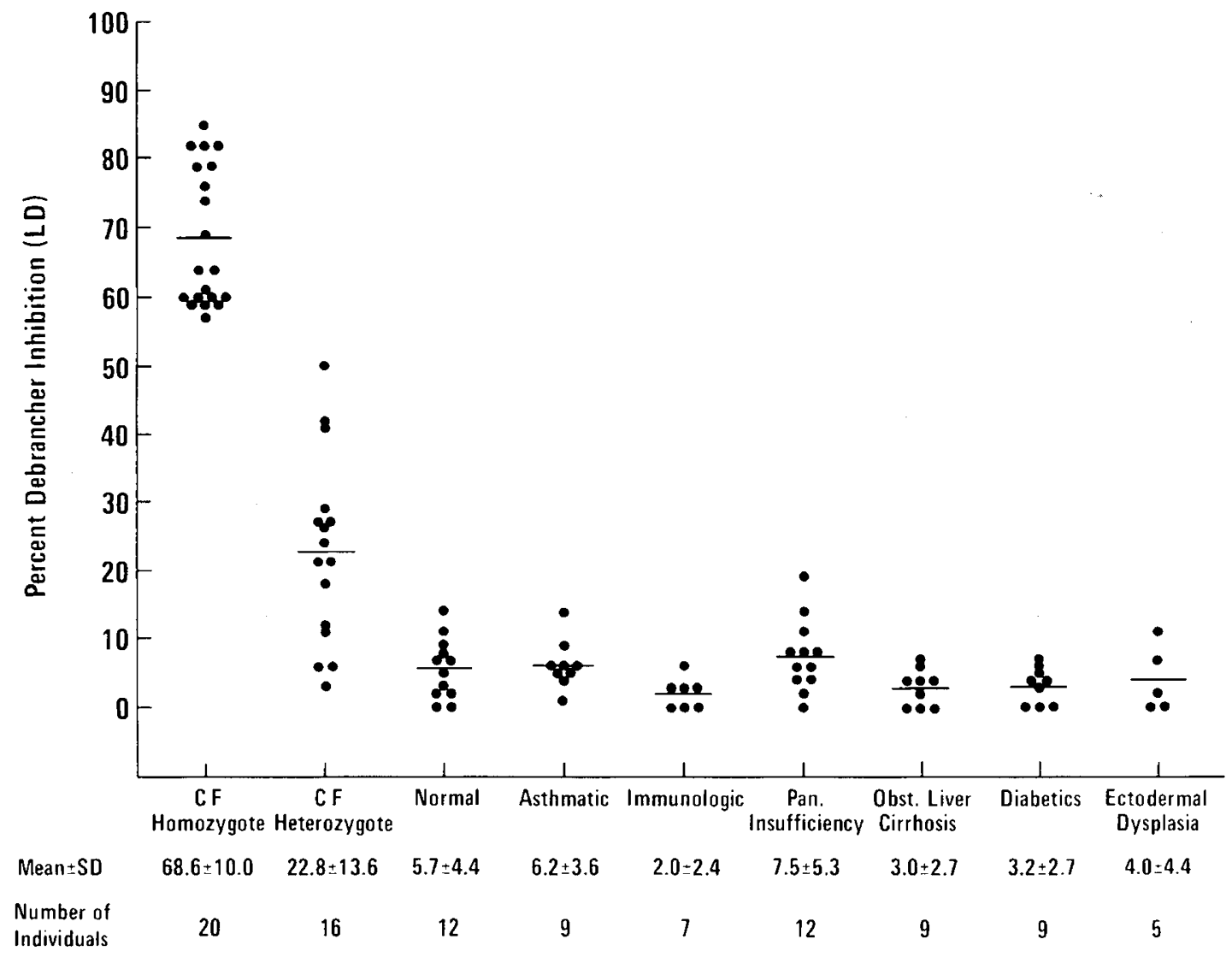

Fig. 1. Presence of salivary factor material isolated from individuals of various patient groups and controls. The factor material was isolated separately from each individual as described in the text. The factor material was detected by the inhibition of glycogen debranching enzyme using glycogen phosphorylase limit dextrin as a substrate in the standard $10 \mathrm{~min}$ assay as described in the text. Horizontal bars, mean. Zero percent inhibition represents an optical density value of approximately 0.250 , the CF homozygote mean an optical density value of 0.079 , the CF heterozygote mean an optical density value of 0.193 , and the normal mean an optical density value of 0.235 . Zero time control optical density values were $0.000 \pm 0.005$. The CF heterozygote group consisted of 15 females and one male with a range in age of 31 to 54 years. $\bullet$, different patient sample.

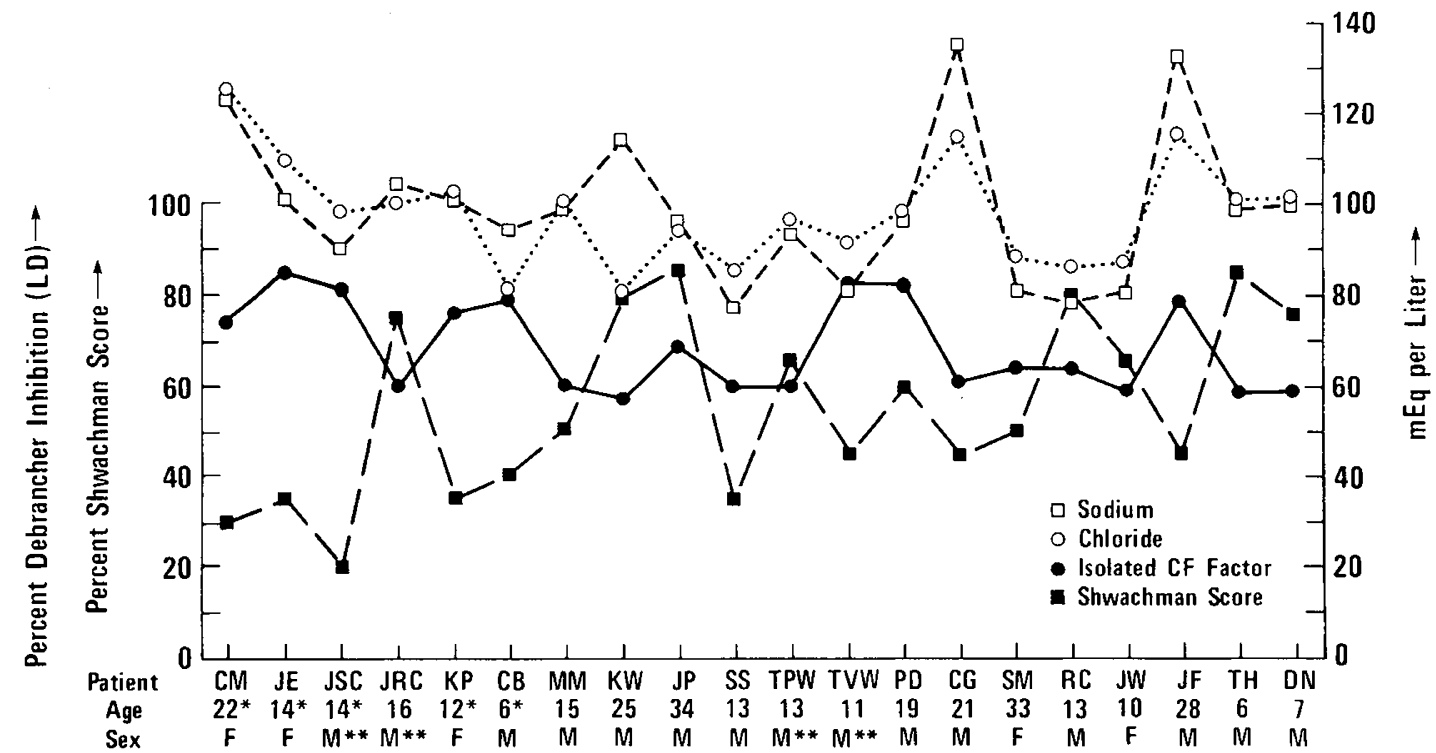

Fig. 2. Correlation of the level of salivary factor isolated from individual CF patients with their clinical evaluation scores and sweat test data. The Shwachman-Kulczycki scores and the sweat test were performed as referenced in the text. A Shwachman-Kulczycki score of $100 \%$ is considered excellent. Sweat electrolyte levels above $60 \mathrm{mEq} /$ liter are considered in the CF range $(28,31)$. The CF patients' scores ranged from minimal (25\%) to severe pulmonary involvement $(30 \%)$ and minimal $(25 \%)$ to severe pancreatic insufficiency $(20 \%)$. None of the patients had significant liver involvement or diabetes. The age at the time the sample was taken and sex of the individual are given. ${ }^{*}$, now deceased; ${ }^{* *}$, siblings. The CF homozygote patients were the same as shown in Figure 1. 
Table 1. Repetitive determination of isolated CF factor material ${ }^{1}$

\begin{tabular}{lcc}
\hline \multicolumn{1}{c}{ Patient } & No. of samples & $\begin{array}{c}\text { \% debrancher inhibi } \\
\text { (limit dextrin) }\end{array}$ \\
\hline CF homozygotes & & \\
& & \\
J. S. C. (M-14) & & \\
J. R. C. (M-16) & 5 & $83.0 \pm 3.8^{3}$ \\
C. B. (M-6) & 6 & $64.8 \pm 5.9$ \\
M. M. (M-15) & 6 & $76.0 \pm 4.5$ \\
K. W. (M-25) & 4 & $55.8 \pm 5.6$ \\
S. S. (M-13) & 6 & $58.3 \pm 3.9$ \\
P. D. (M-19) & 6 & $68.5 \pm 6.8$ \\
R. C. (M-13) & 6 & $77.5 \pm 6.4$ \\
D. N. (M-7) & 4 & $73.5 \pm 9.0$ \\
J. L. (F-14) & 5 & $61.6 \pm 5.0$ \\
& 3 & $84.3 \pm 5.0$
\end{tabular}

CF heterozygotes

$\begin{array}{llr}\text { P. N. (F-41) } & 4 & 34.5 \pm 6.6 \\ \text { C. C. (F-54) } & 3 & 33.7 \pm 6.4 \\ \text { K. B. (F-33) } & 4 & 20.3 \pm 6.2 \\ \text { P. B. (F-47) } & 4 & 9.6 \pm 7.0 \\ \text { R. W. (F-39) } & 4 & 2.3 \pm 2.9 \\ \text { J. H. (F-31) } & 3 & 26.0 \pm 6.0\end{array}$

Normals

$\begin{array}{lll}\text { J. I. }(\mathbf{M}-28) & 7 & 3.6 \pm 4.5 \\ \text { R. E. }(M-23) & 5 & 5.4 \pm 4.5\end{array}$

${ }^{1}$ Reproducibility of inhibition by salivary factor material isolated from $\mathrm{CF}$ homozygote and heterozygote individuals and controls. The factor material was isolated separately from each individual as described in the text. The factor material was detected by the inhibition of glycogen debranching enzyme using glycogen phosphorylase limit dextrin as a substrate in the standard $10 \mathrm{~min}$ assay as described in the text. The samples from each individual were obtained on a random basis over a period of several weeks.

${ }^{2}$ Age and sex are given in parentheses.

${ }^{3}$ Mean \pm S.D.

lation in either age or sex between the amount of factor present in an individual CF homozygote or heterozygote sample or, in the case of homozygotes, in the severity of disease. This is illustrated in Figure 2. There was also no correlation with sweat electrolyte levels (31), the Schwachman-Kulczycki score (33), and major organ complications. The CF patients analyzed in Figure 2 are the same group shown in Figure 1.

\section{DISCUSSION}

The results shown in Figure 1 indicate that all of the $\mathrm{CF}$ homozygote values are significantly higher (20) and separated from all of the other values in the other groups. In the case of the CF heterozygote values, statistical analysis indicates (Table 2) that the data show a normal distribution, with a median about midway between the normal range ( 0 to 14\%) and the $\mathrm{CF}$ patient range (57 to 85\%). This type of distribution would be expected on the basis of the autosomal recessive nature of the CF genetic trait (10) if the presence of the factor material were dependent in some way on the CF gene. This general pattern is typical of autosomal recessive disorders in cases in which it has been possible to measure the levels of mutant gene product, such as in type III glycogen storage disease (limit dextrinosis) (14). Such a pattern reflects the fact that in the heterozygote only one of the genes is affected (10).

The clear separation of CF homozygote (patient) values seen in Figure 1 was not found when the salivary factor was isolated by the heparin-complex method $(12,15)$. Because heparin $(0.05$ to
Table 2. Statistical analysis of patient groups ${ }^{1}$

\begin{tabular}{lrcc}
\hline \multicolumn{5}{c}{ Analysis of variance $^{2}$} \\
\hline \multicolumn{5}{c}{ Source of variation } & $\begin{array}{c}\text { Sum of } \\
\text { squares (SS) }\end{array}$ & $\begin{array}{c}\text { Degrees of free- } \\
\text { dom (DF) }\end{array}$ & $\begin{array}{c}\text { Mean } \\
\text { squares } \\
\text { (MS) }\end{array}$ \\
\hline Between groups & 61922.0519 & 8 & 7740.2565 \\
Within groups (error) & 5543.5849 & 90 & 61.5954 \\
Total & 67465.6370 & 98 & - \\
\hline \multicolumn{5}{c}{ Kruskal-Wallis test for single factor analysis of variance by ranks ${ }^{3}$} \\
\hline Group & No. & Mean rank & \\
\hline 1 & 20 & 89.50 & \\
2 & 16 & 65.56 & \\
3 & 12 & 37.88 & \\
4 & 9 & 41.50 & \\
5 & 12 & 44.71 & \\
6 & 9 & 26.44 & \\
7 & 9 & 25.17 & \\
8 & 7 & 19.50 & \\
9 & 5 & 29.10 &
\end{tabular}

${ }^{1}$ Analysis of patient groups in Figure 1. Statistical analysis of differences between groups using one-way analysis of variance, Student-NewmanKeuls post hoc comparison, and Kruskal-Wallis analysis of variance by ranks as described in the text. Group 1 is CF homozygotes; group 2 is CF heterozygotes; group 3 is normal controls; group 4 is asthmatic and allergic bronchitis patients; group 5 is immunologic deficiency patients; group 6 is pancreatic insufficiency patients; group 7 is obstructive liver cirrhosis patients; group 8 is diabetic patients; group 9 is ectodermal dysplasia patients.

${ }^{2} F=125.66 ; F$-probability $=0.0000$.

${ }^{3}$ Cases, 99; $\chi^{2}, 69.176$; significance, $-0.000 ; \chi^{2}$ corrected for ties, 69.536 ; significance corrected for ties, 0.000 .

$3.0 \%$ ) alone or in the presence of the isolated CF factor material has no effect on the debranching enzyme and the number of substances known to interfere with the enzyme is small $(13,29)$, the specificity to $C F$ observed here apparently resides in the method of isolation of the factor material rather than in the method of assay.

The fact that some of the non-CF values (Fig. 1) are somewhat outside the range of experimental error in the assay method $( \pm 5 \%)$ may attest to the fact that there is at present no method for detecting CF heterozygotes aside from their being known as the parents of a CF homozygote. The absence of a family history of CF in these non-CF individuals does not ensure that they are normal.

The finding that there was no correlation with sweat electrolyte levels, the Shwachman-Kulczycki score, or major organ complications would be anticipated on the basis of the negative findings among the non-CF groups shown in Figure 1 and the apparent association of the factor with the CF gene as exemplified by the autosomal recessive pattern of the CF homozygote and heterozygote values. The possibility that the isolated factor material is derived from the medication given the $\mathrm{CF}$ patients seems unlikely for several reasons. The various CF patients studied (Figs. 1 and 2) varied widely in both the type and extent of medication they received during the interval that samples were taken. These differences were not reflected in the values obtained upon repetitive assays conducted on the same individual (Table 1) or in the amount of factor present among the various CF patients (Fig. 2). In addition, three of the $C F$ patients received no medication during the interval when samples were collected. It is also difficult to explain the presence of the factor in the CF carriers on this basis because they were not on any medication during the interval tested. The possibility that the isolated CF factor material could be produced by chronic Pseudomonas aeruginosa respiratory involvement can be discounted on the basis that four of the CF 
patients tested had no $P$. aeruginosa involvement during the interval studied, and the CF carriers were asymptomatic. The possibility that the isolated CF factor material was related in some way to contact with the pancreatic extracts commonly given to CF patients again is not likely because some of the CF patients had not received such extracts for 3 or 4 years. Furthermore, the majority of the non-CF patients with pancreatic insufficiency tested (Fig. 1) had been receiving varying amounts of pancreatic extracts for a number of years before the saliva samples were taken, and yet they did not show the presence of an isolatable factor material.

The initial concentration of factor in whole saliva and whether it is all bound to $\alpha$-amylase cannot be determined by the debranching enzyme inhibition assay because the presence of $\alpha$ amylase in the saliva interfaces with the debranching enzyme assay method by degrading limit dextrin. For this reason, the debranching enzyme inhibition assay for the factor cannot be used clinically for evaluation or diagnosis of untreated patient samples. The overlapping of $C F$ heterozygote values with normal values also prevents the assay from being used as a means of determining whether or not an individual is a CF heterozygote.

\section{CONCLUSION}

These results clearly indicate that the salivary CF factor material isolated by the glycogen-complex method is specific to CF. They also indicate that the quantity of the factor material present is in some way dependent on the CF gene and that it is not associated with non-CF chronic disease states similar to $\mathrm{CF}$ or produced as a result of the pathologic alterations in those organs commonly affected by $C F$.

\section{REFERENCES AND NOTES}

1. Bishop, S. H., Reinig, M. J., and Doggett, R. G.: Chromatographic isolation of cystic fibrosis salivary isoamylases, p. 25 (Cystic Fibrosis Club Abstracts, San Francisco, 1973).

2. Bowman, B. H., Lockhart, L. H., and McCombs, M. L.: Oyster ciliary inhibition by cystic fibrosis factor. Science (Wash. D. C.), 164: 325 (1969).

3. Conover, J. H., Conod, E. S., and Hirschhorn, K.: Ciliary-dyskinesia factor in immunological and pulmonary disease. Lancet, $1: 1194$ (1973).

4. Davis, P. B., and Di Sant'Agnese, P. A.: A review. Cystic fibrosis at forty-quo vadis? Pediatr. Res., 14: 83 (1980).

5. Di Sant'Agnese, P. A., and Davis, P. B.: Research in cystic fibrosis. N. Engl. J. Med., 295: 481, 534, 597 (1976)

6. Doggett, R. G., and Harrison, G. M.: Cystic fibrosis: reversal of ciliary inhibition in serum and saliva by heparin. Tex. Rep. Biol. Med., 31: 687 (1973).

7. Doggett, R. G., and Harrison, G. M.: Cystic fibrosis: in vivo reversal of the ciliostatic character of serum and parotid secretions by heparin. Cystic fibrosis: in vitro reversal of the ciliostatic character of serum and salivary secretions by heparin. Nat. New Biol., 243: 250, 251 (1973).

8. Doggett, R. G., and Harrison, G. M.: (Unpublished results).

9. Domonkos, A. N.: Some genodermatoses. The chromosome basis of human heredity. In: Andrews' Diseases of the Skin. Ed. 6, p. 687 (W. B. Saunders Co., Philadelphia, 1971).

10. Engel, E.: In: J. B. Stanbury, J. B. Wyngaarden, D. S. Fredrickson: The Metabolic Basis of Inherited Disease. Ed. 4, p. 54 (McGraw-Hill Book Co., Inc., New York, 1978)

11. Gibson, L. E., and Cooke, R. E.: A test for concentration of electrolytes in sweat in cystic fibrosis of the pancreas by iontophoresis utilizing pilocarpine. Pediatrics, 23: 545 (1959).

12. Gillard, B. K., Feig, S. A., Harrison, G. M., and Nelson, T. E.: Cystic fibrosis: Enzymatic detection of a ciliostatic factor. Pediatr. Res., 10: 907 (1976).

13. Gillard, B. K., and Nelson, T. E.: The use of substrate model inhibitors to study the mechanism of action of rabbit muscle amylo-1,6-glucosidase/4- $\alpha$-glucanotransferase. Biochemistry, 16: 3978 (1977).

14. Howell, R. R.: The glycogen storage diseases. In: J. B. Stanbury, J. B. Wyngaarden, D. S. Fredrickson: The Metabolic Basis of Inherited Disease. Ed. 4, p. 137 (McGraw-Hill Book Co., Inc., New York, 1978).

15. Impero, J. E.. Harrison, G. M.. and Nelson, T. E.: Cystic fibrosis: isolation and physical properties of a salivary cystic fibrosis factor. Pediatr. Res., 12: 108 (1978).
16. Impero, J. E., Harrison, G. M., and Nelson, T. E.: Specificity of an isolated salivary factor to cystic fibrosis. p. 10 (Cystic Fibrosis Club Abstracts, New York, 1978).

17. Impero, J. E., Harrison, G. M., and Nelson, T. E.: A low molecular weight peptide associated with a salivary cystic fibrosis factor. p. 47 (Cystic Fibrosis Club Abstracts, Atlanta, 1979).

18. Impero, J. E., Harrison, G. M., and Nelson. T. E.: Isolation, purification and physical properties of a salivary cystic fibrosis factor, p. 56 (Cystic Fibrosis Club Abstracts, San Francisco, 1977).

19. Impero, J. E., Harrison, G. M., and Nelson, T. E.: The specificity of an isolated factor-peptide complex to cystic fibrosis. p. 64 (Cystic Fibrosis Club Abstracts, San Antonio, 1980).

20. Keuls, M.: Student-Newman-Keuls statistical evaluation. Euphytica, 1: 112 (1952).

21. Kruskal, W. H., and Wallis, W. A.: Analysis of variance by ranks. J. Am. Stat. Assoc., 47: 583 (1952).

22. Lilliefors, H. W.: On the Kolmogorov-Smirnov statistical evaluation test for normality with mean and variance unknown. J. Am. Stat. Assoc., 62: 399 (1967).

23. Lockhart, L. A., and Bowman, B. H.: Assay for detection of the cystic fibrosis gene. Tex. Rep. Biol. Med., 31: 631 (1973).

24. Lowry, O. H., Rosebrough, N. J., Farr, A. L., and Randall, R. J.: Protein measurement with the Folin phenol reagent. J. Biol. Chem., 193: 265 (1951).

25. Loyter, A.. and Schramm, M.: The glycogen-amylase complex as a means of obtaining highly purified $\alpha$-amylases. Biochim. Biophys. Acta, 65: 200 (1962).

26. McCombs, M. D.: Research in cystic fibrosis. Tex. Rep. Biol. Med., 31: 615 (1973).

27. Miller, G. L.: Protein determination for large numbers of samples. Anal. Chem. 31: 964 (1959).

28. Nadier, H. L., Rao, G. J. S., and Taussig, L. H.: Cystic fibrosis. In: J. B. Stanbury, J. B. Wyngaarden, D. S. Fredrickson: The Metabolic Basis of Inherited Disease. Ed. 4, p. 1683 (McGraw-Hill Book Co., Inc., New York, 1978).

29. Nelson, T. E., Kolb, E., and Larner, J.: Purification and properties of rabbit muscle amylo-1,6-glucosidase/oligo-1,4 $\longrightarrow$ 1.4-transferase. Biochemistry, $8: 419$ (1969).

30. Robinson, G. C., Miller, J. R., and Bensimon, J. R.: Familial ectodermal dysplasia with sensori-neural deafness and other anaomalies. Pediatrics, 30: 797 (1962).

31. Sawyer, C. S., Scott, A. V., and Summer, G. K.: Cystic fibrosis of the pancreas: a study of sweat electrolyte levels in thirty-six families using pilocarpine iontophoresis. South. Med. J., 59: 197 (1966).

32. Schmoyer, I. R., Fishcher, J. F., and Brooks, S. P.: Fractionation of oyster cilia inhibitor from cystic fibrosis heterozygote serum. Biochem. Biophys. Res. Commun., 46: 1923 (1972).

33. Shwachman, H., and Kulczycki, L. L.: Long-term study of one hundred five patients with cystic fibrosis. Am. J. Dis. Child., 96: 6 (1958).

34. Spock, A., Heick, H. M. C., Cress, H., and Logan, W. S.: Abnormal serum factor found in patients with cystic fibrosis of the pancreas. Pediatr. Res.. 1: 173 (1967).

35. Watts, T. E., and Nelson, T. E.: An improved purification procedure for rabbit muscle amylo-1,6-glucosidase/oligo-1,4 1,4-glucantransferase. Anal. Biochem., 49: 479 (1972).

36. Zar, J. H.: Biostatistical Analysis. (Prentice-Hall, Inc., Englewood Cliffs, NJ. 1974).

37. The Human Subject Protection Committees at The Institute for Rehabilitation and Research and Baylor College of Medicine have approved the procedures for collection of saliva.

38. The authors thank the staff of The Institute for Rehabilitation and Research (T.I.R.R.) Cystic Fibrosis Center and the Pediatric Clinic at Texas Children's Hospital for assistance in collecting patient data. We thank Drs. D. Y. Graham and C. J. Wilson of the Departments of Pediatrics and Medicine, Baylor College of Medicine, for permitting access to patients with liver cirrhosis pancreatic insufficiency, and diabetes and Drs. B. R. Mackler and D. H. Andrews of the Dental Science Institute and the Department of Restorative Dentistry, University of Texas Dental Branch, Houston, for access to patients with immunological deficiency and ectodermal dysplasia. We also thank Drs. J. H. Chalmers and C. T. Caskey of the Departments of Biochemistry and Medicine, Baylor College of Medicine. Dr. R. R. Howell of the Department of Pediatrics, University of Texas Medical School, Houston, and Dr. D. A. Johnston, Department of Biomathematics, M. D. Anderson Hospital and Tumor Institute, University of Texas Health Science Center at Houston, for helpful discussions regarding the interpretation of these results.

39. Requests for reprints should be addressed to: T. E. Nelson, Ph.D., Fleming Department of Rehabilitation, Baylor College of Medicine, Texas Medical Center-T.I.R.R., Houston, Texas 77030 (USA).

40. This research was supported in part by funds from the United States Public Health Service, National Institutes of Health (AM-17524, HR-7-2921) and the Cystic Fibrosis Foundation.

41. Received for publication June 1, 1979.

42. Accepted for publication September 3, 1980. 